\title{
Impaired Male Meiosis and Multiple Associations in Chaerophyllum L. from the Western Himalayas, India
}

\author{
Sanjeev Kumar ${ }^{1 *}$, Santosh Kumari ${ }^{2}$ and Raghbir Chand Gupta ${ }^{2}$ \\ ${ }^{1}$ College of Horticulture and Forestry, Neri Hamirpur 177001, India \\ ${ }^{2}$ Department of Botany, Punjabi University, Patiala 147002, India
}

Received November 19, 2014; accepted June 10, 2015

\begin{abstract}
Summary We present a cytological study of species of the genus Chaerophyllum L. (Apiaceae) by analysing five accessions covering three species from the Western Himalayas, India. The species are collected and studied for detailed male meiosis, multiple associations and pollen fertility. All the studied species exist at diploid level (based on $x=11$ ), and show a meiotic chromosome count of $2 n=22$ at diakinesis and metaphase-I, and regular chromosome distributions at anaphases-I/II. C. aromaticum is reported for the first time from India and found to be in conformity with the earlier reports of $2 n=22$ from outside India. Out of three studied species, two (C. acuminatum and $C$. aromaticum) showed the presence of multiple chromosomal associations at metaphase-I of meiosis-I. The paper herein discusses for the first time the occurrence of multiple associations in these species. The course of meiosis in all studied species shows impaired meiotic course in the form of cytomixis, chromatin stickiness, laggards and chromatin bridges. Abnormal microsporogenesis results in heterogeneous-sized pollen grains and reduced pollen fertility.
\end{abstract}

Key words Meiotic abnormality, Multiple association, Chaerophyllum, Western Himalayas.

The genus Chaerophyllum, belonging to Apiaceae family, comprises of about 110 species which includes annual and perennial herbal plants widely distributed in the temperate and subtemperate zones of Asia, Africa and Europe (Davis 1972, Duman 2000). In India, it is represented by five species (Aswal and Mehrotra 1984). The genus is characterized by stems usually with bristles at the base and swollen below the nodes; leaves pinnate with bristles or hairs; flowers white usually polygamous; fruits cylindrical. The species of the genus have medicinal importance as $C$. temulum is used as a resolutive, curative and stimulant (Agelet and Vallès 2001).

In diploid taxon, the association of more than two chromosomes is indicative of the fact that nonhomologous chromosome pairs have some common segments. The phenomenon is attributed to the presence of heterozygosity for chromosomal interchanges. Structural heterozygosity and ring formation was first observed in Oenothera rubrinervis by Gates (1908), and the earliest record of cytological demonstrations between non-homologous chromosomes has been provided by McClintook (1930). Since then, this phenomenon has been reported by a number of cytologists working on different Angiospermic plants (Biswas and Biswas 1997) with Rhoeo spathacea var. variegata of Commelinaceae being the most common example (Hieronim 2011). According to Mahama and Palmer (2003), reciprocal translocations, also known as chromosomal interchanges, are a type of chromosomal aberrations arising from the exchange of broken segments of nonhomologous chromosomes. Further, these associations appear in the form of rings (closed form) and/or chains (open forms). During the course of cytomorphological explorations in the Western Himalayas, we found multiple associations of four chromosomes in two species of genus Chaerophyllym, i.e.,

*Corresponding author, e-mail: koundelsanjeev@gmail.com

DOI: $10.1508 /$ cytologia.80.311 
Table 1. Information on accession number, habit, locality with altitude, meiotic chromosome numbers, ploidy level, meiotic course, pollen fertility, average pollen size and previous reports of the genus Chaerophyllum L. from the Weatern Himalayas, India.

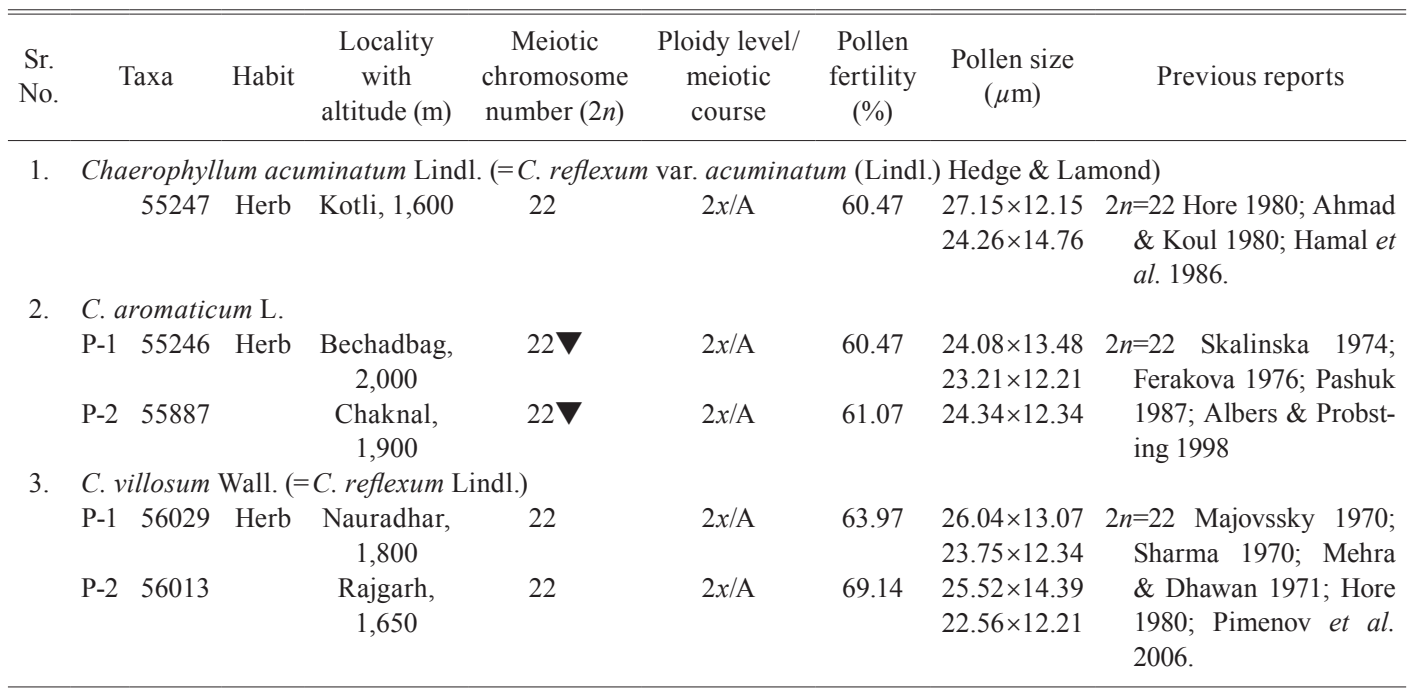

Chaerophyllum acuminatum and C. aromaticum. The aim of the current work was to assess the chromosome number, chromosomal associations, course of meiosis and pollen fertility.

Materials and methods

For meiotic study, flower buds were collected from different localities of selected areas of the Western Himalayas (Table 1). Smears of flower buds were made after fixing with Carnoy's fixative using standard acetocarmine technique. Pollen fertility was estimated by mounting mature pollen grains in glycero-acetocarmine $(1: 1)$. Well-filled pollen grains with stained nuclei were deemed fertile, and shrivelled and unstained pollen grains were counted as sterile. Photomicrographs of pollen mother cells and pollen grains were made from freshly prepared slides using a Nikon 80i Eeclipse Digital Imaging System. Voucher specimens are deposited in the Herbarium of the Department of Botany, Punjabi University, Patiala, India (PUN).

\section{Results}

Detailed meiotic studies on population basis have been carried out on five populations covering three species belonging to the genus Chaerophyllum from different localities with altitudinal range of $1200-2400 \mathrm{~m}$. The data regarding accession number, habit, locality with altitude, meiotic chromosome numbers, ploidy level, meiotic course, pollen fertility, average pollen size of the presently worked out species on population basis are presented in Table 1.

C. acuminatum Lindl. (C. reflexum var. acuminatum (Lindl.) Hedge \& Lamond) is characterised by stem nearly $100 \mathrm{~cm}$, more or less hairy; leaves hairy, 1- or 2-pinnate; leaflets nearly oblong, regularly toothed; rays 4-12. In the studied area it grows as a common plant on moist places between the altitudes of $1200-2400 \mathrm{~m}$. Flowering and fruiting is seen during the months of June to August.

Meiotic studies of this species reveal the chromosome number of $2 n=22$ counted from 11 bivalents at M-I (Fig. 1) confirming the previous reports of $2 n=22$ (Ahmad and Koul 1980) from different parts of the Western Himalayas. 


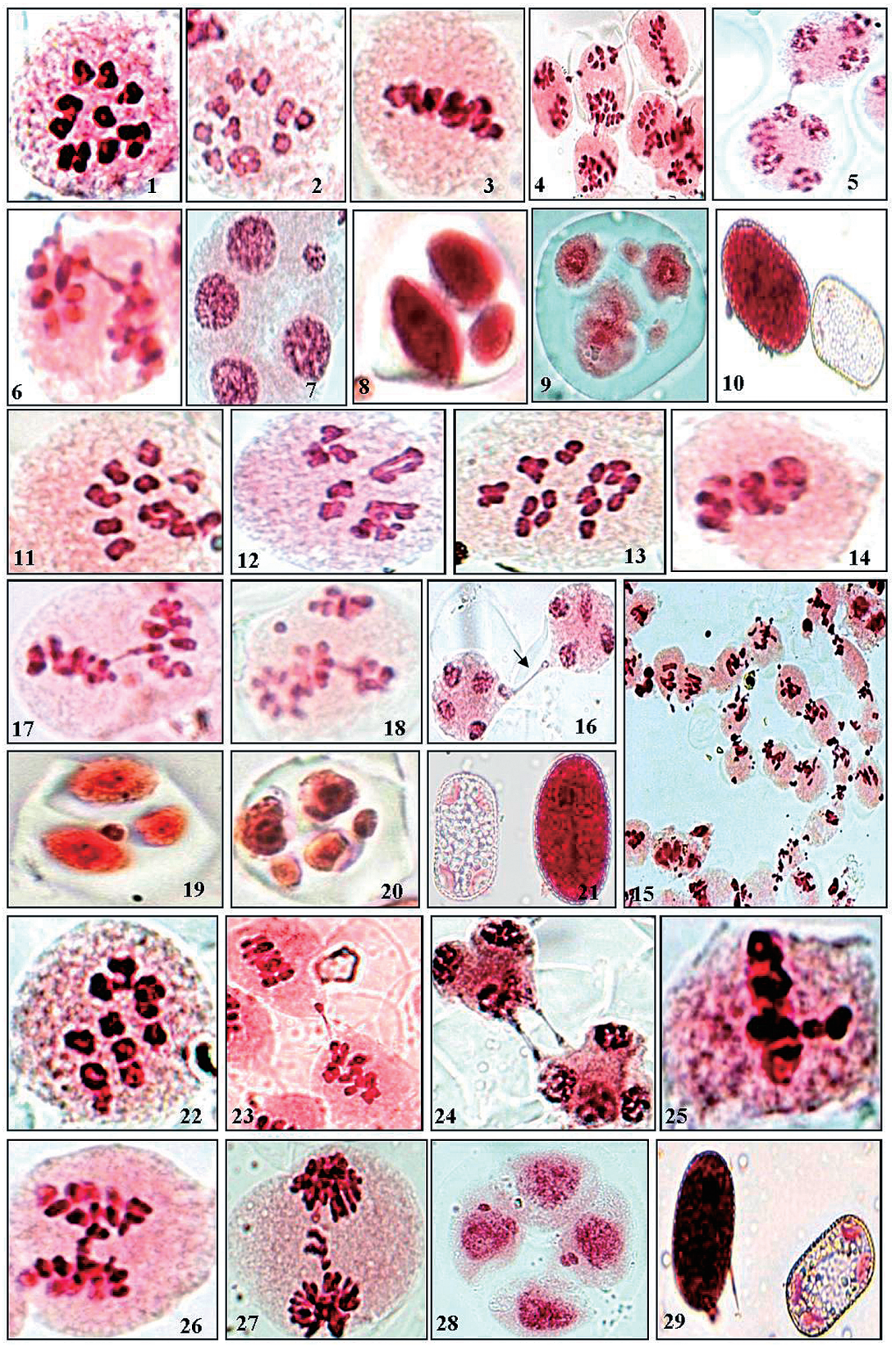

Figs. 1-29. 1-10: Chaerophyllum acuminatum Lindl. Meiosis in PMCs $(2 n=22)$. 1) M-I showing $11_{\mathrm{II}}$. 2) PMC showing 9II+1IV configuration at M-I. 3) Chromatin stickiness at M-I. 4-5) Group of PMCs showing cytomixis at M-I. 6) Bridge at A-I. 7) Laggard at T-II. 8) A triad. 9) A tetrad with micronuclei. 10) Fertile and sterile pollen grains. 11-21: C. aromaticum L. Meiosis in PMCs $(2 n=22)$. 11) M-I showing $11_{\mathrm{II}}$. 12) PMC showing 9II+1IV configuration at M-I. 13) PMC showing 7II+2IV configuration at M-I. 14) Chromatin stickiness at M-I. 15-16) Group of PMCs showing cytomixis. 17) Bridge at A-I. 18) Laggard at A-II. 19) A triad with micronucleus. 20) A tetrad with micronucleus. 21) Fertile and sterile pollen grains. 22-29: C. villosum Wall. Meiosis in PMCs $(2 n=22)$. 22) M-I showing $11_{\mathrm{II}}$. 23-24) Cytomixis at M-I and T-II respectively. 25) Chromatin stickiness at M-I. 26) Bridge at A-I. 27) Laggard at late A-I. 28) A tetrad with micronucleus. 29) Fertile and sterile pollen grains. 
Table 2. Data on cytomixis and meiotic course in various species of Chaerophyllum.

\begin{tabular}{|c|c|c|c|c|c|}
\hline \multirow[b]{2}{*}{$\begin{array}{l}\text { Accession } \\
\text { number }\end{array}$} & \multicolumn{2}{|c|}{ Cytomixis } & \multicolumn{3}{|c|}{ Meiotic course showing PMCs with } \\
\hline & $\begin{array}{l}\% \text { of PMCs involved } \\
\text { Meiosis-I/Meiosis-II }\end{array}$ & $\begin{array}{c}\text { Number of } \\
\text { PMCs involved }\end{array}$ & $\begin{array}{c}\text { Chromosomal } \\
\text { stickiness at M-I (\%) }\end{array}$ & $\begin{array}{c}\text { Bridges at } \\
\text { Meiosis-I/ } \\
\text { Meiosis-II (\%) }\end{array}$ & $\begin{array}{c}\text { Laggards at } \\
\text { Meiosis-I/ } \\
\text { Meiosis-II (\%) }\end{array}$ \\
\hline \multicolumn{6}{|c|}{ C. acuminatum Lindl. } \\
\hline 55247 & $\begin{array}{l}5.55(5 / 90) / \\
2.56(2 / 78)\end{array}$ & $2-4$ & $6.14(7 / 114)$ & $\begin{array}{c}3.44(3 / 87) / \\
-\end{array}$ & $\begin{array}{l}6.74(6 / 89) / \\
3.48(3 / 86)\end{array}$ \\
\hline \multicolumn{6}{|c|}{ C. aromaticum $\mathrm{L}$. } \\
\hline 55246 & $\begin{array}{c}8.73(9 / 103) / \\
-\end{array}$ & $2-3$ & $4.16(5 / 120)$ & $\begin{array}{c}2.10(2 / 95) / \\
-\end{array}$ & $\begin{array}{l}7.05(6 / 85) / \\
1.13(1 / 88)\end{array}$ \\
\hline 55887 & $\begin{array}{l}3.12(3 / 96) / \\
3.29(3 / 91)\end{array}$ & $2-3$ & $3.94(3 / 76)$ & $\begin{array}{l}2.22(2 / 90) / \\
2.04(2 / 98)\end{array}$ & $\begin{array}{c}4.46(5 / 112) / \\
-\end{array}$ \\
\hline \multicolumn{6}{|c|}{ C. villosum Wall. } \\
\hline 56029 & $\begin{array}{l}5.81(5 / 86) / \\
1.11(1 / 90)\end{array}$ & $2-3$ & $4.31(5 / 116)$ & $\begin{array}{c}3.29(3 / 91) / \\
-\end{array}$ & $\begin{array}{l}4.70(4 / 85) / \\
2.24(2 / 89)\end{array}$ \\
\hline 56013 & - & - & $4.20(5 / 119)$ & $\begin{array}{c}2.22(2 / 90) / \\
-\end{array}$ & $\begin{array}{c}5.35(6 / 112) / \\
2.32(2 / 86)\end{array}$ \\
\hline
\end{tabular}

Figures in parenthesis denote observed number of abnormal PMCs in the numerator and number of PMCs observed in the denominator.

C. aromaticum L. is an erect, branched, less hairy herb with leaves 1- to 2-pinnate, pinnae linear to lanceolate; margin regularly toothed; flowers white; bracts absent and rays 4-12 (Fig. 11). It grows as a common plant along roadsides between the altitudes of 1400-2400 m. Flowering and fruiting is seen during the months of June to September.

The present chromosome count of $2 n=22$ counted from 11 bivalents at M-I (Fig. 36/178b) is reported for the first time from India and found to be in conformity with the earlier reports of $2 n=22$ from outside India.

C. villosum Wall. (=C. reflexum Lindl.) is characterised by root thick, fleshy, spindle shaped; stem $80-100 \mathrm{~cm}$; leaves large, varying in size, hairy, 3-pinnate; leaflets pinnatified, irregularly segmented, toothed and rays $3-6$. It also grows as a common plant along roadsides between the altitudes of 1400-2400 m. Flowering and fruiting is seen during the months of June to August.

During meiosis, 11 bivalents have been observed at M-I (Fig. 22). The present meiotic chromosome count of $2 n=22$ is in conformity with the earlier records from India (Mehra and Dhawan 1971, Pimenov et al. 2006) and from outside India.

All the above discussed five populations of the three species of Chaerophyllum show highly abnormal meiotic course (Table 2). The cytomixis involves transfer of chromatin between proximate PMCs, seen right from the Prophase-I to T-II (Figs. 4, 5, 15, 16, 23, 24; Table 2). The chromosomal stickiness either involved a few bivalents or the whole complement forming clump at M-I (Figs. 3, 14, 21; Table 2). Other associated meiotic abnormalities are observed in the form of chromatin bridges and laggards (Figs. 6, 7, 17, 18, 26, 27; Table 2) at various stages of MeiosisI/II. Besides these abnormalities, multiple associations of chromosomes have been seen at M-I in C. acuminatum and C. aromaticum, where four chromosomes are associated to form ring (Figs. $2,12,13)$. All these abnormalities cause abnormal microsporoensis, leading to the formations of triads, tetrads and polyads with or without micronuclei (Figs. 8, 9, 19, 20, 28; Table 3). Heterogeneous sized fertile and sterile pollen grains have also been observed in these species (Figs. 10, 21, 29). 
Table 3. Data on abnormal microsporogenesis in various species of Chaerophyllum.

\begin{tabular}{|c|c|c|c|c|c|}
\hline \multirow{3}{*}{$\begin{array}{c}\text { Accession number } \\
\text { polyads }\end{array}$} & \multicolumn{5}{|c|}{ Microsporogenesis (Values in \%) } \\
\hline & \multicolumn{2}{|c|}{ Triads } & \multicolumn{2}{|c|}{ Tetrads } & \multirow[t]{2}{*}{ Polyads } \\
\hline & WMN & WM & WMN & WM & \\
\hline \multicolumn{6}{|c|}{ C. acuminatum Lindl. } \\
\hline 55247 & $5.26(6 / 114)$ & $1.75(2 / 114)$ & $85.08(97 / 114)$ & $7.89(9 / 114)$ & - \\
\hline \multicolumn{6}{|l|}{ C. aromaticum $\mathrm{L}$. } \\
\hline 55246 & - & $2.54(3 / 118)$ & $90.67(107 / 118)$ & $5.08(6 / 118)$ & $1.69(2 / 118)$ \\
\hline 55887 & $3.37(3 / 89)$ & $1.12(1 / 89)$ & $88.76(79 / 89)$ & $6.74(6 / 89)$ & - \\
\hline \multicolumn{6}{|l|}{ C. villosum Wall. } \\
\hline 56029 & - & - & $90.90(80 / 88)$ & $6.81(6 / 88)$ & $2.27(2 / 88)$ \\
\hline 56013 & - & - & $87.50(91 / 104)$ & $7.69(8 / 104)$ & $4.80(5 / 104)$ \\
\hline
\end{tabular}

Figures in parenthesis denote observed number of abnormal PMCs in the numerator and number of PMCs observed in the denominator.

\section{Discussion}

As per cytological literature of the genus, it is revealed that 25 species are cytologically known on world level $(2 n=12,14,22,24)$ with $62.50 \%$ showing polyploidy. The genus is reported to be tribasic $(x=6,7,11)$ with 11 as the primary basic number. Out of five taxonomically known species from India, all the three cytologically worked out species are diploids $(2 n=22)$. According to Burnham (1956) the high frequency of chains is attributed to either extremely short interchange pieces, or early terminalisation of chiasmata or chiasma failure in one of the arms during meiosis of structural heterozygotes. Reciprocal translocations have been considered to be an important genetic aberration for both geneticists and plant breeders as these are the sources of intraspecific chromosomal structural polymorphism (Candela et al. 1979). Presently, multiple associations of chromosomes have been found in Chaerophyllum acuminatum and C. aromaticum, where chromosomes are associated to form rings and chains during M-I. In C. acuminatum and C. aromaticum four chromosomes are associated in the form of a ring as observed at M-I indicating that for interchanges, only two non-homologous pairs of chromosomes are involved.

\section{References}

Agelet, A. and Vallès, J. 2001. Studies on pharmaceutical ethnobotany in the region of Pallars (Pyrenees, Catalonia, Iberian Peninsula). Part I. General results and new or very rare medicinal plants. J. Ethnopharmacol. 77: 5770.

Ahmad, I. and Koul, A. K. 1980. In: IOPB chromosome number reports LXVIII. Taxon 29: 543.

Aswal, B. S. and Mehrotra, B. N. 1984. Flora of Lahaul-Spiti (A Cold Desert in Northwest Himalaya). Bishen Singh Mahendra Pal Singh, Dehra Dun.

Biswas, S. C. and Biswas, A. K. 1997. Induced translocation heterozygosity and sterility in Lathyrus sativus L. Bangladesh J. Bot. 26: 131-136.

Burnham, C. R. 1956. The use of chromosomal interchanges to test for the independence of linkage groups established genetically. In: Proceedings of the International Genetics Symposia. Tokyo and Kyoto. pp. 453-456.

Candela, M., Figueiras, A. M. and Lacadena, J. R. 1979. Maintenance of interchange heterozygosity in cultivated rye, Secale cereale L. Heredity 42: 283-289.

Davis, P. H. 1972. Flora of Turkey and the East Aegean Islands, Vol. 4. Edinburgh University Press, Edinburgh. p. 312.

Duman, H. 2000. Chaerophyllum L.: Flora of Turkey and the East Aegean Islands, Vol. II. A. Edinburgh University Press, Edinburgh.

Gates, R. R. 1908. A study of reduction in Oenothera rubrinervis. Bot. Gaz. 115: 336-342. 
Hieronim, G. 2011. Cytogenetics of the permanent translocation heterozygote Rhoeo spathacea var. variegata. Implications for complex chromosome rearrangements in Rhoeo. Caryologia 64: 325-334.

Mahama, A. A. and Palmer, R. G. 2003. Translocation breakpoints in soybean classical genetic linkage groups 6 and 8. Crop Sci. 43: 1602-1609.

McClintook, B. 1930. A cytological demonstration of the location of an interchange between two non- homologous chromosomes of Zea mays. Proc. Natl. Acad. Sci. U.S.A. 16: 791-796.

Mehra, P. N. and Dhawan, H. 1971. In: IOPB chromosome number reports. XXXIV. Taxon 20: 785-797.

Pimenov, M. G., Alexeeva, T. V. and Kljuykov, E. V. 2006. In: IAPT/IOPB chromosome data 2. Taxon 55: 1-6. 